NOTAS

AMOR Y MUNDO DE JOAQUÍN XIRAU

Miguel García Jaramillo*

En enero de 1937 Joaquín Xirau impartió en la Sorbona una conferencia con motivo de una reunión conjunta de las sociedades francesas de Psicología y de Filosofía. El contenido de ese acto fue publicado bajo el título L'amor i la percepció dels valors. Esto, sumado al quehacer intelectual llevado a cabo en las reuniones filosóficas del Seminario de Pedagogía de la Universidad de Barcelona, dio lugar a una obra realmente sabia -sin deseo de adulación ni de utilizar demasiados adjetivos-: Amor y mundo. Si se me permite una confesión personal, por más de dos décadas me he dedicado a la filosofía. He podido reconocer en muy buena parte los textos aludidos por Xirau, que constituyen una fuente común de ambos: Platón, Aristóteles, los Padres de la Iglesia, Des-

* Departamento Académico de Estudios Generales, ITAM. cartes, Kant, Nietzsche, Bergson, Freud, Scheler, etc. Sin embargo, nunca había visto la centralidad del concepto del amor a través de la historia de la filosofía, ni me había percatado de las diferencias que ha sufrido a través de su evolución, ni menos aún hubiera podido utilizar un lenguaje tan apasionante, sencillo y claro, lleno de imágenes y metáforas, que no desdicen en absoluto -sino todo lo contrario- su profundidad intelectual. Como decía Ortega y Gasset, "la claridad es la cortesía del filósofo”.

Aunque Joaquín Xirau pretendía con Amor y mundo hacer una presentación de "algunas dificultades descriptivas" previas a toda discusión ontológica de las mismas, ${ }^{1}$ es claro que el autor desbordó con esa obra

${ }^{1}$ Joaquín Xirau, Amor y mundo, 1998, Madrid, Fundación Caja Madrid y Antropos Editorial, prefacio, p. 135. 
sus expectativas originales. Si bien es cierto que no da solución a algunos de los problemas metafísicos que el concepto del amor plantea en la actualidad, también es verdad que expone las diferentes respuestas metafísicas -y refuta otras- dadas a través del tiempo y que nos deja no ya en el umbral de las respuestas, sino en la antesala.

La obra que reseñamos puede dividirse en dos partes. Somos conscientes que ambas no resultan departamentos estancos y que ambos aspectos se encuentran entrecruzados. Sin embargo, es claro que en la primera, que comprendería los capítulos I-IV, encontramos un mayor acento en una historia o evolución del concepto del amor; y en la segunda-capítulos V-VII- vemos una exposición del pensamiento propio del autor.

\section{Evolución histórica del concepto de amor}

Joaquín Xirau distingue cuatro etapas históricas del concepto del amor. La antigüedad griega, su evolución a través del cristianismo, el Renacimiento, y la idea actual, dominada en buena parte por el pensamiento positivista. Igual que en la división del libro, vemos que Xirau ha marginado algunos elementos subordina- dos que se entrecruzan, ${ }^{2}$ aunque reconocemos que en buena parte la nota dominante se encuentra en la síntesis presentada por él.

\section{El amor en el mundo griego}

El mundo griego en general, sea en su versión mítica, platónica o aristotélica, "reduce el amor a la pasión". 3 Para las concepciones religiosas orientales antiguas, visiones del mundo que "resuenan todavía de un modo claro en la doctrina de Platón”, el alma humana, aunque de naturaleza divina, "se halla prisionera del cuerpo y de las formas tenebrosas de la materia. La caída del alma en el mundo lleva forzosamente consigo un anhelo de liberación (...). La concupiscencia, el amor carnal, el apetito de las cosas terrenas, se interpone constantemente entre el afán y su término, y mantiene al alma en una lucha que provoca el dolor y la angustia (...). Sólo la muerte es capaz de redimirnos del 'pecado de haber nacido’ (...). El auténtico amor rechaza toda concupiscencia terrestre y nos elevan (...) por la muerte progre-

${ }^{2}$ El mismo autor manifiesta que "no aspira a una precisión de carácter etnográfico e histórico” y que más bien atenderá a "la atmósfera espiritual”. Joaquín Xirau, op. cit., p. 137.

${ }^{3}$ Ibid., p. 138. 
NOTAS

siva y deliberada de todo afán y todo deseo particular, a la esfera luminosa en la cual, mediante la renuncia a toda felicidad terrena, alcanzamos la verdadera y auténtica beatitud”. ${ }^{4}$

“¿Cuál es el origen de la insatisfacción eterna del hombre sobre la tierra y del anhelo infinito que lo lleva más allá de sí mismo y de la realidad que lo circunda?"5 Según Joaquín Xirau para el mundo antiguo "nada es en sí y por sí. Todo anda fuera de sí. Todo es fugaz, transitorio, pasajero, evanescente (...). Dondequiera que intente fijar los pies, se desmorona el suelo. Si buscamos en la vida algo que la aliente y merezca una consagración entera y confiada no la hallamos en este mundo". ${ }^{6}$

No obstante, para Platón, las personas y las cosas de este mundo "ofrecen en su misma transitoriedad signos de plenitud (...). Si no fuera posible entrever algo permanente a través de la fulguración transitoria, ni tan siquiera tendría sentido pronunciar palabras y atribuirles una significación (...). Puesto que hablamos y nos entendemos y coincidimos en la unidad de una significación (...) es evidente que en la palabra va implícita la luz"7 o estabilidad. Estas

${ }^{4}$ Ibid.

${ }^{5}$ Ibid., p. 139

${ }^{6}$ Ibid., p. 140.

${ }^{7}$ Ibid. son las ideas platónicas, paradigmas de las realidades cambiantes de este mundo. "Las cosas del mundo adquieren su realidad y su valor porque aspiran eternamente a ser, sin alcanzarlo nunca, aquella que las ideas eternamente son (...). Este anhelo que (...) se funda (...) en la aspiración constante de lo fugaz a lo eterno, es lo que Platón denomina amor." ${ }^{8}$ En el Banquete, Platón afirma que "el amor no es un dios como suponen los interlocutores. Hijo de la riqueza y de la pobreza, no es un dios o un hombre (...). [Si fuera totalmente rico], ya no aspiraría a nada, ni es enteramente pobre porque la perfecta indigencia es la perfecta infecundidad (...). El amor no se halla ni en la perfecta eternidad ni en la perfecta movilidad. Es justamente la movilidad que aspira a la eternidad. No es un dios ni es un hombre. Es un demonio -un mensajero- que pone a los hombres en contacto con Dios". ${ }^{9}$

Joaquín Xirau finaliza su exposición de Platón diciendo: "El término del amor no es, por tanto, la persona [la cual] es todavía un grado intermediario. No es un fin en sí misma. Es un medio para llegar a un fin. La belleza pura, en su realidad impersonal e inmóvil, es el último término de todo afán. A partir de la fuerza

\footnotetext{
${ }^{8}$ Ibid., p. 141.

${ }^{9}$ Ibid., p. 142.
} 
dionisíaca nos hemos elevado a la serenidad de Apolo. La eternidad a la cual se aspira no se halla ni en las cosas del mundo ni en el ser anhelante de las personas, sino en el cuadro inmutable de las ideas." 10

Como dice José Luis Abellán, “la función ontológica del amor se manifiesta [en la cultura griega] más que en el Timeo, en la culminación de la Metafísica de Aristóteles". ${ }^{11}$ Para el Estagirita, Dios, en tanto causa final de todo, "mueve en cuanto es amada”. ${ }^{12}$ Pero ¿qué es el movimiento para Aristóteles? Por un lado, "el apetito que lleva a las cosas mundanas a la persecución de su lugar natural”; ${ }^{13}$ pero por otro, y más profundo, este apetito "es un reflejo del reino de lo sobrenatural gobernado por la razón”, ${ }^{14}$ por el lógos. Dios, intelección de intelección (noesis noeseos) es motor en cuanto que es objeto del deseo; pero su perfección le impide aspirar a nada. Así, "Eros y lógos -prosigue Joaquín Xirauson dos aspectos correlativos de la misma realidad. El amor promueve

\footnotetext{
${ }^{10}$ Ibid., p. 144.

${ }^{11}$ José Luis Abellán, El exilio filosófico en América. Los transterrados de 1939, 1998, México, FCE, p. 50.

${ }^{12}$ Met. 1072b 3, cfr. Joaquín Xirau, op. cit., p. 144.

${ }^{13}$ Cfr. Joaquín Xirau, op. cit., p. 146.

${ }^{14}$ Ibid.
}

el conocimiento. El conocimiento resulta del afán erótico y se apodera, mediante la ascensión dialéctica, de las esencias que estructuran la realidad. Pero, en el orden ontológico, lógos ocupa el primer lugar. El delirio erótico es eterna insatisfacción". ${ }^{15}$ Así, "el amor queda excluido de Dios (...). Puesto que todo lo tiene, no puede aspirar a nada. No es posible afirmar que el mundo es obra del amor de Dios (...). El amor, así concebido, excluye, por definición, la misericordia, la compasión, la simpatía (...). El mundo siempre anhelante, nunca satisfecho (...) es en sí mismo (...) movido. No es activo, sino pasivo (...). Es el reino de las pasiones (...). El motor inmóvil, libre de toda pasión, es pura actividad”. ${ }^{16}$

${ }^{15}$ Ibid., p. 147.

${ }^{16}$ Ibid., p. 147. Aunque sin duda la exposición de Xirau es fiel al pensamiento de Aristóteles, también es cierto que el filósofo griego sugiere que Dios conoce al mundo, cuando en De anima afirma: “A la doctrina de Empédocles, por su parte, le ocurre además que Dios resulta ser el más ignorante: sólo él, desde luego, desconoce uno de los elementos -el Odio- mientras que los seres mortales conocen todos, por estar constituidos de todos ellos” (I, 1, 410b 5-7.) Asimismo, Hegel también considera que la providencia -entendida en términos hegelianos, no católicos- es una consecuencia de los textos aristotélicos. Su punto de partida es igualmente la Metafísica (I, 2, 
NOTAS

\section{El amor en la espiritualidad cristiana}

Para Joaquín Xirau, igual que para Nietzsche, el cristianismo representa una trasmutación de los valores, aunque de significación positiva, a diferencia de este pensador alemán. En cuanto al tema que nos ocupa, Xirau reúne dos tesis que constituyen la diferencia específica del cristianismo: “En el principio era el Verbo” y “Dios

983a 1-3), que parafrasea: "Si el nombre de Dios no ha de ser vano, debemos reconocer que Dios es bondadoso, o sea, que se comunica. En las antiguas representaciones de los griegos, Dios es pensado como envidioso y se habla de la envidia de los dioses y de que la divinidad es hostil a lo grande y de que las sentencias de los dioses rebajan las cosas grandes. Aristóteles dice que los poetas mienten mucho; que no se puede atribuir envidia a Dios. Si afirmásemos, pues, que Dios no se comunica, esto sería atribuir a Dios envidia. Dios no puede perder por comunicación, como una luz no pierde porque se encienda otra en ella" (Lecciones sobre la filosofía de la historia universal, 1953, Madrid, Revista de Occidente. La misma idea está desarrollada en Lecciones sobre la historia de la filosofía, p. 255). Con estos argumentos se podría probar un conocimiento divino del mundo según Aristóteles, pero queda pendiente si ese Dios ama el mundo, lo cual no encontramos en este filósofo. es amor”. El lógos y el Eros -o Charitas- ya no se contraponen. Para el cristianismo, "no es posible ya que el amor sea hijo de la pobreza y de la riqueza [como pretende Platón en el Banquete]. Nada tiene que ver con la pobreza ni con el espíritu de ganancia. Es plena riqueza, la única verdadera y auténtica riqueza. Hijo exclusivo de la plenitud y de la abundancia, se identifica con la plenitud suprema. No es un demonio. Es la esencia de Dios". ${ }^{17}$

Por lo que respecta al amor a las criaturas, la persona "no es un caso particular ni un ejemplo, sino una calidad original e irreductible; un tesoro intransferible, válido por sí mismo. La virtud no se halla en limitarse, sino en enriquecerse. No se enaltece la vida por su consagración a los valores impersonales, sino por la entrega incondicional a las personas. No es la persona reflejo de entidad alguna sobrepersonal, ni el individuo de la comunidad. No hay más hombre que el hombre individual. La persona es la jerarquía suprema". ${ }^{18}$

Xirau añade: "nada más erróneo que atribuir al cristianismo el origen de la actitud ascética que para afirmar la vida en otro mundo huye de éste y lo niega. Esta salvación por la fuga

\footnotetext{
${ }^{17}$ p. 155.

${ }^{18}$ Joaquín Xirau, op. cit., p. 151.
} 
(...) tiene su fuente en las concepciones dualistas del día y la noche propia de las religiones primitivas (...). En la tradición cristiana, por la inclinación amorosa de Dios sobre el mundo y por su presencia personal en él, la salvación se hace posible ya en este mundo (...). Todo merece amor por el solo hecho de existir. Símbolo de esta actitud es 'el hermano lobo' de san Francisco y la infantil alegría de toda la vida franciscana" ${ }^{19}$

\section{El concepto renacentista del amor}

Pero esta visión del amor, del mundo, del hombre y la divinidad, que Joaquín Xirau goza ejemplificando con san Agustín, san Francisco, santo Tomás y Dante, se disuelve con el racionalismo. En el siglo XVII, para filósofos como Malebranche, Spinoza y Leibniz, "el mundo es el cálculo de Dios. Dios es el matemático supremo. Tal como dios lo calculó, así es el mundo. El mundo no es obra del amor de Dios, sino cálculo de la mente divina”. ${ }^{20}$ Nuevamente encontramos la escisión entre lógos y Charitas. Sin embargo, "el mundo que se revela en los grandes sistemas racionalistas, conserva todavía el esplendor y la

${ }^{19}$ Ibid., p. 157.

${ }^{20}$ Ibid., p. 171. dignidad de las viejas tradiciones metafísicas y religiosas"; ;1 bastará un paso más para que se pierda todo con el surgimiento de las nuevas ciencias positivas.

\section{El concepto del amor para las ciencias positivas}

Para las ciencias positivas "se exige que lo complejo se explique por lo simple, lo grande por lo pequeño, lo superior por lo inferior". ${ }^{22}$ Contrasta esta postura con la tradición greco-cristiana, para quienes lo "inferior recibía su sentido y su ser por su referencia a lo superior". ${ }^{23}$

Sin duda alguna el principio que nos dice: en las explicaciones no hay que multiplicar los entes sin necesidad obedece a un criterio de economía difícil de refutar, y se puede encontrar ya en Aristóteles o Tomás de Aquino. Sin embargo, se ha aplicado abusivamente cuando sí hay necesidad de ir más allá de las explicaciones sencillas, desembocando así en la historia del pensamiento en simplificaciones exageradas, que violan muchas veces la experiencia y en otras ocasiones algunos principios más fundamentales, amputando

\footnotetext{
${ }^{21}$ Ibid.

${ }^{22}$ Ibid., p. 176.

${ }^{23}$ Ibid.
} 
NOTAS

entidades, potencias o dinamismos cuando son requeridos.

Aunque los orígenes de esta visión puedan remontarse a 'la navaja de Ockham', el antecedente próximo mencionado por Xirau es Darwin, "quien destituye al hombre de su centro espiritual”. ${ }^{24}$ Pero sin duda esta visión es más representativa en los casos de Nietzsche y Freud.

Joaquín Xirau hace ver que para los susodichos autores "en lo que respecta al amor, no sólo los fenómenos de la vida intersexual (...) sino también aquellos que dan lugar a las más altas manifestaciones de la vida de la cultura -el amor a la ciencia, el amor al arte, la adoración religiosa o el éxtasis místico-, no son sino el resultado de una serie de mecanismos mediante los cuales, los impulsos poderosos que dominan las zonas profundas de nuestro ser llegan, a través de una serie de etapas de represión y sublimación, a la producción de una luminosidad radiante, pero superficial e inoperante". ${ }^{25}$ En efecto, ya en Más allá del bien y del mal Nietzsche criticó la versión cartesiana de lo que llama 'voluntad de verdad', sometiéndola a la 'voluntad de poder' y como una variación suya; pero por su parte, también Freud presenta al amor esencialmen-

${ }^{24}$ Ibid.

${ }^{25}$ Ibid., p. 175. te como una prurito liberado por la descarga, y en sus formas más elevadas (como en el caso de la amistad que surge entre los novios o esposos, lo cual no tiene siempre ni necesariamente su satisfacción en lo sexual) como una tendencia entorpecida o, en el mejor de los casos, como sublimación del instinto sexual. "El naturalismo -dirá Joaquín Xirau- en todas sus formas, desde Spinoza hasta Freud (...) no ha consistido en otra cosa que en la amputación de una de las aspiraciones fundamentales de la vida, la reducción de la segunda aspiración a la primera, del valer al ser, de toda cosa a cualquier cosa y la consiguiente supresión de la realidad autónoma del movimiento amoroso."26

\section{La propuesta de Joaquín Xirau}

No podemos dejar de observar un dejo de frustración en las palabras de Xirau cuando concluye el tratamiento de ese momento histórico que constituye el positivismo en sus diversas modalidades, pero que preparan la revancha para el próximo capítulo. Personalmente para Joaquín Xirau, "frente a las realidades de la experiencia es posible adoptar

${ }^{26}$ Joaquín Xirau, op. cit, p. 182. 
dos actitudes cardinales y polarmente opuestas: la actitud amorosa [vale decir de la tradición greco-cristiana] y la actitud rencorosa, la actitud afirmativa y la actitud negativa, la que todo lo salva y la que todo lo aniquila". 27

La tradición greco-cristiana “destaca en el mundo los valores positivos, los ordena y coordina poniéndolos al servicio de algo y en una conspiración de servicios, al servicio de algo que tiene consistencia y valor por sí. Interpretado con amor todo adquiere realce. El mundo se incorpora y se pone de pie. Incluso lo insignificante adquiere valor al servicio de lo valioso y aun lo repugnante y repelente -el estiércol al servicio de la flor y el fruto, las secreciones al servicio de una persona, de sus empresas e ideales-. Considerado con amor todo se dignifica -el placer y los órganos corporales y, en lo que respecta al amor sexual, los órganos y las actividades sexuales y sus funciones más desagradables (...). Claro que es posible interpretar las flores y los frutos y el jardín por los excrementos que les prestan savia y [claro que es posible interpretar] la mirada amorosa por los mecanismos de las secreciones internas. Esto es lo propio de la mirada rencorosa. Ante la mirada rencorosa o indiferente, lo

${ }^{27}$ Ibid., p. 208. superior se pone al servicio de lo inferior y por este mero hecho queda aniquilado". ${ }^{28}$

Contra Nietzsche, Joaquín Xirau afirma que "el amor supone abundancia de vida interior (...). El amor, en su fuente cristiana más auténtica, es (...) una virtud de fuertes". ${ }^{29}$

Para Nietzsche, "toda actitud amorosa (...) deriva (...) de una tendencia que arranca de la compasión y de la piedad”. La glorificación cristiana "de los mansos y humildes, de los pobres, miserables y hambrientos (...) y en general de los débiles, representaría una inversión radical de los valores que lleva fatalmente a una concepción decadente de la vida y la sumisión de lo superior a lo inferior". ${ }^{30}$

Para Xirau, "el amor es una realidad específica e irreductible", ${ }^{31}$ aunque siempre se encuentre mezclado con apetitos, impulsos, tendencias, emociones, pasiones, simpatías e incluso con la compasión. Pero en sí mismo "nada más distinto del amor que las tendencias biológicas de simpatía o compasión (...). Aunque en ocasiones se compliquen y se confabulen con el amor, no se confunden con él, y en una cierta medida se le

\footnotetext{
${ }^{28}$ Ibid., p. 209.

${ }^{29}$ Ibid., p. 199.

${ }^{30}$ Ibid., p. 200.

${ }^{31}$ Ibid., p. 199.
} 
NOTAS

oponen incluso lo niegan. No se funda el amor en la compasión. Por el contrario, la compasión y la piedad sólo adquieren sentido y dignidad en una conciencia previamente impregnada de amor. La bienaventuranza de los que lloran no es una invitación al llanto universal. Es más bien todo lo contrario: la aptitud de la vida amorosa para hallar, incluso en el llanto, la ventura y la alegría”. ${ }^{32}$

El punto fundamental de la crítica a Nietzsche se encuentra, pues, en la visión diametralmente opuesta del amor interpretado como pasión por el filósofo alemán. Ahora bien, para Xirau "el amor no es pasión, sino acción”. " Las inclinaciones, los impulsos simpáticos o las pasiones “dependen de un influjo y un contagio. No salen de nosotros mismos. Nos sentimos arrastrados por ellos. Nos sujetan, nos mueven nos inclinan. De ahí el nombre de inclinaciones. No somos en ellas activos, sino pasivos. [Las inclinaciones y los impulsos simpáticos] pertenecen al régimen de las pasiones. El amor no es pasión, sino acción. No depende inicialmente de las circunstancias ni de las inclinaciones de los demás. Es iniciativa y espontaneidad, entrega gratuita y sin intención ni esperanza de recompensa ni aun de correspondencia. De ahí

${ }^{32}$ Ibid., p. 200.

${ }^{33}$ Ibid. que el amor requiere vigor, fuerza, salud, abundancia”. ${ }^{34}$

\section{Conclusión}

La importancia en general de la obra de Joaquín Xirau y del tema del amor en especial, rebasa por mucho los intereses especulativos y académicos, para adquirir particular relevancia no sólo en los temas psicológicos y existenciales, sino también en los sociales. Él mismo ya afirmaba, "Nos hallamos en plena barbarie. El hombre actual posee medios poderosísimos. Carece de fines claros, de ideales capaces de exigir la sumisión incondicional de la vida. Grave error es hablar de decadencia. ¿Decadencia de qué? Difícilmente en ningún momento de la historia se ha manifestado una vitalidad más vigorosa. Podemos hacerlo casi todo. No sabemos, empero, qué hacer."

Con estos términos, Joaquín Xirau manifiesta la nota de los grandes hombres: su preocupación por lo social. Esa preocupación que manifestaba Ortega ya en sus Meditaciones del Quijote: "yo soy yo y mi circunstancia, y si no la salvo a ella no la salvo yo”. Es decir, conciencia de que el hombre sólo dota de sentido a su existencia en la medida en que se la

${ }^{34}$ Ibid., p. 200-201. 
dota a su circunstancia, a su familia, a su barrio, a su ciudad, a su pueblo, a sus alumnos. En su vida práctica, Joaquín fue testimonio claro de esta persuasión. Esto se manifiesta académicamente por sus conferencias por toda Europa; por sus magisterios en Salamanca (1927), Zaragoza (1928), Barcelona (1928), Inglaterra (1929) y en México (1940); como Presidente del Patronato Escolar de Barcelona y del Consejo de Segunda Enseñanza de Cataluña (1933), Miembro del Consejo de Cultura de la Generalidad (1933). Pero también se manifiesta en lo político, al fundar con su hermano Josep la Unió Socialista de Ctalunya. Como pionero de instituciones culturales destaca por el Instituto Francés para América Latina (IFAL), del que es miembro fundador en México. Su relevancia como filósofo también se ve en el círculo de alumnos que lo iban a visitar, en cierto modo sus discípulos.

¿Decadencia de qué?, inquiría Joaquín Xirau. Difícilmente se podrá responder sin considerar al amor, que dota de sentido a la existencia, como acción. 